\title{
QUALIFICAÇÃO DA PRÁTICA DOCENTE: A EXPERIMENTAÇÃO DE UM PROCESSO INOVADOR NA FORMAÇÃO DE PROFESSORES DA EDUCAÇÃO BÁSICA.
}

\author{
SÃO PAULO/SP JUNHO/2018
}

\author{
Priscila Bernardo Martins - UNICID - priscila.bmartins11@gmail.com \\ Rita Maria Lino Tarcia - UNIFESP - rtarcia@uol.com.br \\ Julia de Cassia Pereira do Nascimento - UNICSUL - juliacpn@terra.com.br \\ Adriana Domingues Freitas - UNICSUL - adriana.freitas@cruzeirodosulvirtual.com.br \\ Karen Diana Macedo Arsenovicz - UNICID - karendmoa@gmail.com \\ Jane Garcia de Carvalho - UNICSUL - jane@cruzeirodosulvirtual.com.br \\ Edda Curi - UNICSUL - edda.curi@gmail.com
}

Tipo: Relato de Experiência Inovadora (EI)

Categoria: Métodos e Tecnologias

Setor Educacional: EDUCAÇÃO SUPERIOR

\begin{abstract}
RESUMO
Este trabalho é o relato de uma experiência inovadora, e tem como objetivo apresentar a experimentação de utilização de um processo inovador de ensino na formação de professores de educação básica, para o desenvolvimento da disciplina de Prática de Ensino. Escolhemos como foco o curso de Pedagogia - EAD, de uma universidade privada do Estado de São Paulo - SP, em uma perspectiva crítica reflexiva sobre a prática de ensino e a articulação entre teoria e prática na formação dos professores. Com uma pesquisa de abordagem qualitativa, empregamos a pesquisa-ação, com utilização da observação participante, tendo por base a participação nos registros de observações, com pouca ou nenhuma interferência no local investigado. mostrando o desenvolvimento da disciplina em questão, a participação dos alunos e com foco nas ações dos profissionais envolvidos e suas contribuições no processo inicial formativo dos alunos. Nossas análises das participações na disciplina, assim como o feedback dos alunos mostram que a partir das novas estratégias e na experimentação desenvolvida na disciplina de Prática de Ensino foi possível perceber ao sucesso na experimentação aplicada, garantindo assim uma formação de qualidade e confiabilidade mediada pelas Tecnologias Digitais de Informação e Comunicação.
\end{abstract}

Palavras-chave: Experimentação em EAD; Prática de Ensino; Formação de Professores. 


\section{Introdução}

No âmbito da formação de professores, a transformação da práxis é temática relevante e muito presente nas pesquisas e na produção científica da área, buscando subsidiar os professores para o desenvolvimento de ações metodológicas coerentes com o mundo disruptivo no qual as crianças e jovens se inserem.

As Tecnologias Digitais de Informação e Comunicação - TDIC estão em sintonia com o desafio e exigências da formação de professores na contemporaneidade. As TDIC alteram diferentes funções cognitivas e têm modificado a forma como as pessoas acessam a informação e aprendem.

Se antes, o conhecimento estava restrito, ao contexto escolar, nos dias atuais, há uma pluralidade de meios digitais que se distribuem em diferentes ambientes educativos. Dessa forma, a escola, os processos educativos e os professores estão se modificando a fim de atender o perfil desse novo sujeito aprendente, que nasce imerso em tecnologia e traz novas exigências para a Educação. Isso pressupõe que as premissas da formação docente devem ser revistas a fim de o professor assumir novos papéis e ser capaz de mediar novos processos educativos.

O número de instituições de ensino que oferecem o Curso de Pedagogia na modalidade a distância, com o apoio de ambientes virtuais de aprendizagem (AVA) têm crescido influenciado por essas novas demandas e pelo forte desafio de formar o profissional responsável pela formação de crianças e jovens desta nova geração.

No ambiente virtual de aprendizagem, o estudante descobre um espaço que permite integrar múltiplos recursos com muitas possibilidades de aprendizado. Com isso, é importante e necessária a discussão sobre a forma como a prática de ensino é desenvolvida e discutida no âmbito da formação de professores que atuarão na educação básica, alunos da modalidade EAD, como forma de interlocução com os conhecimentos adquiridos durante o curso.

Neste artigo, nos propomos a apresentar a experimentação da disciplina de Prática de Ensino, com foco no curso de Pedagogia-EAD, por ser um dos cursos mais procurados nesta modalidade de ensino. Neste curso é indispensável a presença de um mediador que acompanha o processo de aprendizado do estudante, de modo a favorecer reflexões entre os saberes estudados e discutidos no ambiente virtual de aprendizagem - AVA e a prática profissional vivenciada nos estágios supervisionados. 
A disciplina de Prática de Ensino é o locus dessa discussão e, por esse motivo, o estudante dialoga com o tutor enquanto o mediador das reflexões e interage com um professor responsável que compartilha suas experiências e motiva a construção da identidade docente e da prática do futuro profissional.

Nessa perspectiva, a proposta de compreensão do processo de produção do conhecimento dos estudantes do Curso de Pedagogia-EAD, por meio de uma estratégia didática, voltada para práticas inovadoras, direciona o olhar para a necessária articulação entre teoria e prática com vistas ao fortalecimento da formação docente.

\section{Objetivos}

O presente artigo objetiva apresentar numa perspectiva crítica reflexiva, a experimentação na qual foi utilizada uma metodologia inovadora de ensino para o desenvolvimento da disciplina de Prática de Ensino, do curso de Pedagogia - EAD, de uma universidade privada do Estado de São Paulo - SP. Especificamente, o artigo demonstra as ações dos profissionais envolvidos e suas contribuições no processo inicial formativo, a partir das quais se espera garantir uma formação de qualidade e confiabilidade mediada pelas Tecnologias Digitais de Informação e Comunicação.

\section{Procedimentos Metodológicos}

Este estudo configura-se em uma pesquisa de abordagem qualitativa que, segundo Creswel (2010), utiliza diferentes concepções filosóficas, estratégias de investigação, métodos de coletas, análise e interpretação dos dados. Por se tratar de uma pesquisaação, utilizamos a observação participante, na medida em que os pesquisadores frequentaram os ambientes onde os fenômenos ocorreram, e tendo por base a participação nos "registros de observações, procurando produzir pouca ou nenhuma interferência no local investigado" (FIORENTINI \& LORENZATO, 2012, p. 107).

Acreditamos que esse método é pertinente e possibilita a compreensão dos saberes mobilizados na constituição identitária do estudante, na medida em que a produção do conhecimento é investigada no contexto em que se desenvolvem as práticas de ensino.

\section{Referencial teórico}

As inquietações com as práticas de ensino são constantes nos cursos superiores de Licenciatura. 
O conceito de prática como componente obrigatório é enfatizado nas disposições da Resolução CNE/CP 1, de 18 de fevereiro de 2002, ressaltando que a dimensão da prática deve estar presente na segunda metade do curso. Idealiza-se, portanto, o momento de propiciar aos estudantes a vivência prática profissional em consonância com os conhecimentos teóricos alcançados ao longo do curso.

Sobre tal resolução, Pimenta e Lima (2015), enfatizam que embora a carga horária total do curso seja distribuída em horas práticas, horas de estágio, horas de aulas para conteúdos curriculares de natureza científico-cultural e horas para outras formas de atividades acadêmico-científico-culturais, não há sintonia entre teoria e prática. Ressaltam ainda que, essa dissociação entre estágio, atividades práticas e conteúdos curriculares, reforça o "treinamento de competências e aprendizagem de práticas modelares". Diante disso, a disciplina de Ensino como disciplina acadêmica traz um olhar peculiar sobre o conteúdo, e a prática como componente curricular, um olhar mais específico para sua dimensão prática.

Nesse contexto, passamos a relatar a experimentação realizada no curso de PedagogiaEAD, na disciplina de Prática de Ensino, com os profissionais envolvidos, o desenvolvimento da disciplina e os resultados verificados.

\section{Apresentação e discussão da experimentação}

Conforme já exposto, apresentaremos a seguir como foi desenvolvida a estratégia diferenciada de oferta, acompanhamento e devolutiva às discussões propostas na disciplina de Prática de Ensino no curso de Pedagogia-EAD.

\subsection{Contextualização e estrutura da disciplina Prática de Ensino}

A prática de ensino no curso de Pedagogia-EAD, está prevista a partir do quarto semestre do curso e se constitui disciplina obrigatória do curso de formação de professores. A disciplina em questão possui carga horária total correspondente a 120 horas, sendo desdobrada em três semestres subsequentes.

A disciplina, disponibilizada aos alunos no Ambiente Virtual de Aprendizagem Blackboard - foi organizada com uma estrutura diferenciada, apresentando três núcleos de conhecimentos importantes para a formação do futuro professor polivalente: Educação Infantil, anos iniciais do Ensino Fundamental e Gestão Educacional. A estrutura curricular da disciplina a partir dos três níveis elencados tem oportunizado a potencialização da articulação entre teoria e prática, num movimento onde o conteúdo 
teórico e a prática desenvolvida nos espaços educativos se entrelaçam, o que está de acordo com as orientações do Projeto Pedagógico do curso.

Os três núcleos de conhecimento da disciplina apresentam quatro unidades temáticas descritas no quadro a seguir:

Quadro 2. Núcleos de conhecimento da disciplina de Prática de Ensino no Curso de Pedagogia-EAD

\begin{tabular}{|c|c|c|c|}
\hline $\begin{array}{l}\text { Unidades } \\
\text { temáticas }\end{array}$ & $\begin{array}{l}\text { Prática de ensino em } \\
\text { educação infantil } \\
4 \text { o semestre do curso } \\
\text { Carga horária - } 40 \text { horas }\end{array}$ & 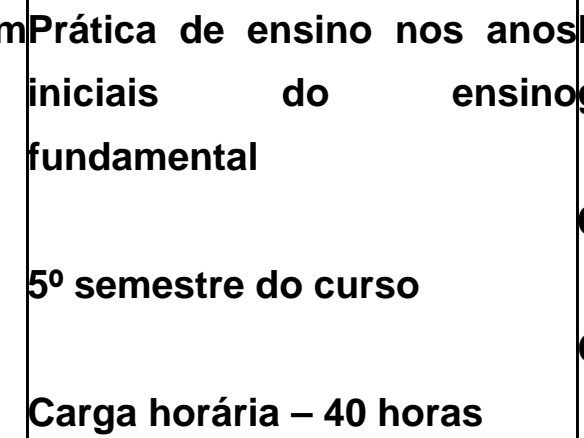 & $\begin{array}{l}\text { spática de ensino em } \\
\text { ogestão educacional } \\
\text { 6o semestre do curso } \\
\text { Carga horária - } 40 \text { horas }\end{array}$ \\
\hline & $\begin{array}{l}\text { A prática de ensino e c } \\
\text { estágio } \\
\text { supervisionado }\end{array}$ & $\begin{array}{l}\text { Prática de Ensino nos anos } \\
\text { ariniciais do Ensino Fundamental } \\
\text { e o Estágio Supervisionado }\end{array}$ & $\begin{array}{llr}\text { sf papel do } & \text { Gestor } \\
\text { Educacional } & \text { e } & 0 \\
\text { Financiamento } & & \text { da } \\
\text { Educação Pública } & & \end{array}$ \\
\hline II & $\begin{array}{l}\text { Música, Contação } \\
\text { Histórias e Artes Visuais }\end{array}$ & $\begin{array}{l}\text { Oralidade e produção textual, } \\
\text { Alfabetização e letramento na } \\
\text { Educação de jovens e adultos } \\
\text { e arte e lúdico }\end{array}$ & $\begin{array}{l}\text { 1, Áreas de atuação da } \\
\text { a|Gestão e } \quad \text { Gestão } \\
\text { s Democrática }\end{array}$ \\
\hline |III & $\begin{array}{l}\text { Natureza e } \\
\text { Iniciação à Alfabetização } € \\
\text { Letramento, Iniciação ac } \\
\text { Numeramento e Pensamentc } \\
\text { Geométrico }\end{array}$ & $\begin{array}{l}\text { e, Ensino de Matemática e uso de } \\
\text { e Tecnologias na Educação } \\
\text { to }\end{array}$ & $\begin{array}{|lrr|}\text { A Prática de } & \text { Ensino e } \\
\text { estágio na } & \text { Gestão } \\
\text { Educacional: } & \\
\text { Coordenador } & \text { Pedagógico } \\
\text { e o Supervisor de } & \text { Ensino } \\
\end{array}$ \\
\hline IV & $\begin{array}{l}\text { Jogos e Brincadeiras, o pape } \\
\text { do espaço físico nc } \\
\text { desenvolvimento da criança } \\
0 \text { professor e a Educação } \\
\text { Inclusiva }\end{array}$ & $\begin{array}{l}\text { el Ensino de História e Geografia, } \\
\text { aleiências Naturais e Meio } \\
\text { a, Ambiente }\end{array}$ & $\begin{array}{l}\text { Trio Gestor, Projeto } \\
\text { Político } \quad \text { Pedagógico, } \\
\text { formação em serviço e e } \\
\text { relações com o trio gestor }\end{array}$ \\
\hline
\end{tabular}

Fonte: Elaborado pelas autoras

Portanto, a partir dessas quatro unidades de estudos, os estudantes têm a possibilidade de articular os conhecimentos construídos durante o curso com as situações concretas 
vivenciadas na realização do estágio obrigatório ou do exercício docente, por meio de atividades práticas em campo profissional Os estudantes são avaliados pelas participações promovidas nos fóruns das unidades que a compõem, considerado instrumento fundamental para que estes atinjam os objetivos propostos na disciplina.

\subsection{Profissionais Envolvidos}

Para a experimentação da nova forma de oferta e operacionalização da disciplina de Prática de Ensino, houve um trabalho colaborativo de um grupo de diferentes profissionais da EAD, com o envolvimento e interação entre os mesmos, visando a formação dos alunos, por meio de efetiva interação entre teoria e prática. Relatamos a seguir cada profissional deste grupo, com suas atividades:

Coordenação Pedagógica da PREAD - Pró-reitoria de Educação a distância Profissional responsável pela assessoria e acompanhamento pedagógico das disciplinas e orientação aos profissionais envolvidos no processo;

Coordenador do Curso - Profissional responsável pela matriz curricular do curso de Pedagogia, validação dos conteúdos elaborados e indicação do professor responsável pela disciplina;

Coordenador de Estágio - Profissional responsável pela gestão do Núcleo de EstágiosEAD, supervisão, orientação e apoio a todos os profissionais envolvidos com o estágio e com a disciplina de Prática de Ensino;

Supervisor de Tutoria - Responsável pelo acompanhamento e assessoria ao trabalho realizado pelos tutores. Esse profissional atende às necessidades formativas dos tutores, propiciando constante formação e qualificação dos mesmos.

Professor Responsável - Profissional responsável pelo acompanhamento dos temas e dúvidas apresentadas nos fóruns da disciplina Prática de Ensino, a partir do levantamento realizado pelos tutores, sistematizando tais discussões, com referencial teórico, criando materiais, tais como textos e vídeos, que serão disponibilizados aos alunos para fechamento dos temas propostos.

Tutor - Responsável pelo acompanhamento dos alunos na disciplina Prática de Ensino, onde são propiciadas reflexões e discussões sobre a formação do professor, além de mediações entre estas discussões e as observações feitas durante a realização do estágio. Promoverá a interação entre teoria e prática, em sintonia com o professor 
responsável da disciplina Prática de Ensino.

Ressaltamos aqui que, embora o grupo seja composto de vários profissionais em diferentes níveis de atuação, não há aqui uma hierarquização organizacional, mas sim um grupo de trabalho onde cada participante dentro de suas funções interage e colabora na experimentação inovadora proposta.

\subsection{A EXPERIMENTAÇÃO NA DISCIPLINA “PRÁTICA DE ENSINO - EAD”}

Nos cursos de formação de professores, especialmente no curso de Pedagogia, a expectativa apresentada pelos estudantes é como aprender a ensinar. Afinal, esta é a competência que esperam conquistar para poder desempenhar o ofício de ser professor. Isso nos leva a refletir sobre a importância da teoria e da prática nesse aprendizado.

Vislumbrando uma experimentação diferenciada em EAD, o grupo de profissionais envolvidos com este processo, propôs o desenvolvimento de uma estratégia inovadora de ensino, constituída por quatro etapas consecutivas, mas que interagem entre si ao longo do desenvolvimento da disciplina.

\subsubsection{Primeira Etapa: Planejar estratégias}

Nesta etapa, o grupo de profissionais envolvidos se reúne para discutir os encaminhamentos, prevendo possíveis imprevistos que poderiam ocorrer durante 0 processo, e redimensionando as ações que se fizerem necessárias, num efetivo movimento de interação entre as distintas áreas de conhecimento, suscitando então, a colaboração, a partilha e o diálogo. Nesta etapa são também analisados os materiais da disciplina, as propostas de fóruns, as expectativas de respostas e participações;

\subsubsection{Segunda etapa: Desenvolver a estratégia: Conduzir, mediar as discussões e coletar dados}

Na segunda etapa, com a participação dos alunos nos fóruns de discussão propostos a cada semestre a partir dos Núcleos de Conhecimento apresentados, o tutor assume a mediação das discussões promovidas, direcionando as reflexões, e fazendo intervenções pontuais, gerenciando o fórum e orientando os alunos a respeito das participações e do conteúdo proposto. Elabora uma síntese elucidativa, visando sistematizar a interlocução estabelecida pelos estudantes entre os conhecimentos teóricos e a experiência em campo de estágio, e encaminha essa síntese para o professor responsável. 


\subsubsection{Terceira etapa: Refletir sobre os dados coletados}

Nesta etapa, o professor responsável, a partir do acompanhamento dos temas, contribuições e dúvidas apresentadas nos fóruns da disciplina Prática de Ensino, e a partir síntese feita pelos tutores, sistematiza tais dados, elaborando um texto crítico e reflexivo, embasado teoricamente. Este texto é a base para a gravação de um vídeo, no qual o professor faz as intervenções necessárias, responde às dúvidas apontadas pelos alunos e sugere leituras, como feedback aos alunos.

\subsubsection{Quarta etapa:Compartilhar devolutivas}

A quinta e última etapa consiste na socialização dos resultados das participações dos estudantes. O vídeo e o texto de apoio elaborados pelo professor são postados na disciplina pelo tutor, disponibilizando aos alunos. Essas socializações de experiências contribuem para construção de novos conhecimentos, criando situações para que os estudantes se posicionem criticamente sobre o seu próprio conhecimento, promovendo mudanças nesse processo contínuo de aprender.

\section{Alguns resultados da experimentação}

Esta experiência foi implantada na Instituição em questão, no curso de Pedagogia-EAD, com vistas à formação docente dos alunos. Sabe-se que a reflexão sobre a prática e a base teórica desta reflexão, são importantes na construção da identidade de cada professor e influenciam sua atuação em sala de aula. Neste sentido, nossas observações sobre os resultados que esta nova experiência propiciou, são de natureza qualitativa. No momento da oferta da disciplina Prática de Ensino neste novo modelo, inovador a nosso ver, tínhamos em mente a qualidade na formação e não a quantidade de participações nos fóruns ou de alunos aprovados.

Os levantamentos feitos pelos tutores a partir das participações dos alunos nos fóruns nos mostraram um amadurecimento dos alunos na articulação com as demais disciplinas do curso, além de aprofundamento nas análises das situações vivenciadas nos estágios, o que nos mostra um avanço na qualidade da formação. Além disso, alguns coordenadores de curso fizeram pesquisas com seus alunos e o resultado foi muito positivo, os alunos se mostraram mais satisfeitos e se disseram que o novo formato está contribuindo para suas reflexões e formação docente. Alguns alunos enviaram mensagem no AVA aos tutores e email à coordenação do Núcleo de Estágios elogiando a experimentação, solicitando a manutenção e novas discussões sobre os temas abordados. 
A partir da oferta da disciplina e do desenvolvimento de cada uma das etapas propostas, entendemos que os objetivos iniciais de uma integração maior entre o grupo de profissionais envolvidos e alunos, assim como articulação entre teoria e prática no curso observado, puderam ser alcançados de forma mais efetiva com a experiência do novo formato da disciplina. Percebeu-se que por meio desta estratégia diferenciada de participação, discussões e devolutivas efetivamente direcionadas para os questionamentos dos próprios alunos, foi assegurado aos mesmos e aos profissionais envolvidos reflexões sobre a própria prática, em uma necessária interação entre a teoria discutida na disciplina de Prática de Ensino, assim como nas demais disciplinas do curso, e as situações práticas vivenciadas nos estágios ou em suas atividades profissionais.

\section{Considerações Finais}

O presente estudo teve por objetivo central relatar, numa perspectiva crítica reflexiva, a experiência inovadora de utilização de uma experimentação diferenciada de ensino no desenvolvimento da disciplina de Prática de Ensino, do curso de Pedagogia - EAD, de uma universidade privada do Estado de São Paulo.

Consideramos que alcançamos tal objetivo ao demonstrar as ações do grupo de profissionais envolvidos e suas contribuições no processo inicial formativo dos alunos, assim como o fluxo de ações de apresentação, participação e devolutivas nos fóruns da disciplina.

Compreendemos que, de fato, numa relação dialética, a ação pedagógica não se concretiza de maneira isolada, mas sim por um processo que envolve a participação coletiva entre todos os sujeitos envolvidos.

O fato da devolutiva dada aos alunos ser disponibilizada em dois formatos - vídeo e texto - a nosso ver também contribuiu para que cada aluno, dentro de suas especificidades de aprendizagem e compreensão, pudesse se apropriar das colocações do professor responsável, refletindo sobre as discussões e fazendo sua própria interação entre a teoria aprendida e a prática vivenciada. Este diálogo entre todos os envolvidos permite esta apropriação e reflexão.

Quando esta interlocução se fortalece, traz ganhos significativos tanto para os profissionais que atuam na universidade, quanto para o aluno, no sentido de potencializar o processo de ensino e aprendizagem. Para além de propiciar o aperfeiçoamento dos conhecimentos docentes, a integração entre os pares possibilita a 
constituição identitária dos futuros professores da educação básica.

Esperamos ter propiciado reflexões à comunidade EAD, na questão de interação teoria e prática, a partir das quais se pode garantir uma formação de qualidade e confiabilidade mediada pelas Tecnologias Digitais de Informação e Comunicação.

\section{Referências}

BRASIL. Conselho Nacional de Educação. Conselho pleno. Resolução CNE/CP 1, de 18 de fevereiro de 2002. Institui diretrizes curriculares nacionais para a formação de professores de educação básica, em nível superior, curso de licenciatura, graduação plena. Brasília, 2002.

CRESWELL, J. W. W. Projeto de pesquisa: métodos qualitativo, quantitativo e misto. 2. ed. Porto Alegre: Bookman, 2010.

FIORENTINI, D.; LORENZATO, S. (2012). Investigação em educação matemática: percursos teóricos e metodológicos. $3^{\underline{a}}$ ed. Campinas: Autores Associados. (Coleção formação de professores).

PIMENTA, S.G; LIMA, M. S. L. Estágio e docência. 5. ed. São Paulo: Cortez, 2015. 